\title{
Insulin resistance in the NIDDM model Psammomys obesus in the normoglycaemic, normoinsulinaemic state
}

\author{
E.Ziv ${ }^{1}$, R.Kalman ${ }^{1}$, K.Hershkop ${ }^{1}$, V. Barash ${ }^{2}$, E.Shafrir ${ }^{2}$, H.Bar-On ${ }^{1}$ \\ ${ }^{1}$ Diabetes Research Unit, Division of Internal Medicine, Hadassah University Hospital, Jerusalem, Israel \\ ${ }^{2}$ Department of Biochemistry, Hadassah University Hospital, Jerusalem, Israel
}

\begin{abstract}
Summary The desert gerbil Psammomys obesus ("sand rat"), a model of nutritionally induced insulin resistance and non-insulin-dependent diabetes mellitus, was treated after weaning with exogenous insulin implants in the normoglycaemic, normoinsulinaemic state. Albino rats matched for weight and age served as high energy diet adjusted reference animals. Insulin administration, elevating the serum insulin to $6000 \mathrm{pmol} / \mathrm{l}$ resulted in only a mild reduction in blood glucose levels in Psammomys, but caused a severe, often fatal hypoglycaemia in the albino rats. The hepatic response to insulin-induced hypoglycaemia in rats involved a significant loss in glycogen and suppression of phosphoenolpyruvate carboxykinase (PEPCK) activity. In Psammomys under similar hyperinsulinaemia no appreciable changes in liver glycogen and PEPCK activity were evident, indicating that blood glucose was replenished by continuing gluconeogenesis. Euglycaemic, hyperinsulinaemic clamp
\end{abstract}

caused a complete shut-down of hepatic glucose production in albino rats. However, in both diabetesprone and diabetes-resistant Psammomys lines, mean hepatic glucose production was reduced by only 62 to $53 \%$ respectively, despite longer lasting and higher levels of hyperinsulinaemia. These results indicate that Psammomys is characterized by muscle and liver insulin resistance prior to diet-induced hyperglycaemia and hyperinsulinaemia. This is assumed to be a species feature of Psammomys, exemplifying a metabolic adjustment to survival in conditions of food scarcity of both animal and human populations. It may reflect a propensity to insulin resistance and hyperglycaemia in population groups exposed to affluent nutrition. [Diabetologia (1996) 39: 1269-1275]

Keywords Insulin resistance, non-insulin-dependent diabetes model, insulin implants, hyperinsulinaemic euglycaemic clamp, hepatic glucose production.
Psammomys obesus (often referred to as the "sand rat") is a desert gerbil lapsing into hyperinsulinaemia and hyperglycaemia when transferred from its native food to laboratory rodent diets [1-3]. Genetic factors predispose it to non-insulin-dependent diabetes mellitus (NIDDM), whereas environmental, mainly

Received: 11 April 1996 and in revised form: 4 July 1996

Corresponding author: Dr. E.Ziv, Diabetes Unit, Department of Medicine, Hadassah University Hospital, Jerusalem 91120, Israel

Abbreviations: NIDDM, Non-insulin-dependent diabetes mellitus; HE, high energy; LE, low energy; HGP, hepatic glucose production; PEPCK, phosphoenolpyruvate carboxykinase; TGT, total glucose uptake nutritional, factors contribute to the expression of the diabetic phenomena. The progression of nutritionally induced diabetes in the Psammomys in many respects resembles the development of insulin resistance and NIDDM in certain human populations, such as Pima Indians, Australian Aborigines, Asian Indians and others [4-6]. Strong evidence supports the view that both insulin resistance and relative insulin deficiency contribute to the evolution of NIDDM. However, it is still not resolved which defect is the earliest cause of the hyperglycaemic syndrome, and whether the same cause applies to all subjects.

The transition of Psammomys to diabetes has been classified into four, often consecutive states [7]: A: normoinsulinaemia and normoglycaemia; B: 
hyperinsulinaemia and normoglycaemia; C: hyperinsulinaemia and hyperglycaemia; D: hyperglycaemia and hypoinsulinaemia, due to the loss of beta-cell insulin secretion capacity.

States B and C are characterized by marked peripheral and hepatic insulin resistance. Evidence of low insulin receptor density in muscle and liver and decreased receptor function in association with hyperinsulinaemia developing on high energy $(\mathrm{HE})$ diets (relative to its native nutritional regimen) have been previously demonstrated [8]. The hyperglycaemia on HE diets has also been related to the large proportion of proinsulin in the circulation, particularly in state $\mathrm{C}$, as a result of beta-cell over-stimulation $[9,10]$. It should be stated though, that the domesticated Psammomys fed a diet rich in fiber and low in digestible carbohydrates remains non-diabetic for prolonged periods [11].

It was the aim of our study to investigate whether, in view of low insulin receptor density and the sensitivity of pancreatic beta-cells to insulin over-secretion [reviewed in 1-3], Psammomys exhibits an inherent, species characteristic, insulin resistance, even in the normoglycaemic, normoinsulinaemic state.

\section{Materials and methods}

Animals. Male Psammomys obesus, and male albino rats of the outbred Sabra strain, from the Hebrew University, Hadassah Medical School Animal Farm, were used. Psammomys and albino rats were weaned at 3 weeks of age to one of two diets: low energy (LE) diet ( $2.38 \mathrm{kcal} / \mathrm{g}$; Koffolk, Petach Tikva, Israel), and a standard rodent maintenance diet which represents a high energy (HE) regimen for Psammomys (2.93 kcal/g; Weizmann Institute, Rehovot, Israel) [11]. Psammomys and rats were housed in individual polypropylene cages. Water and diet were supplied ad libitum. All experimental procedures were authorized by the Institutional Animal Care Committee.

Exogenous insulin administration. Insulin implants (Bovine Insulin, Linshin, Canada) were inserted s.c. to Psammomys or rats into the scurf area. Each implant releases insulin continuously for up to 60 days at a rate of 2 IU/24 h [12]. In the shortterm experiment a group of animals was killed by decapitation after $24 \mathrm{~h}$. Blood was collected for glucose and insulin assays. Liver was excised for glycogen and enzyme activity measurements. In the long-term experiment the animals were killed in the fed state after 14 days. Blood glucose, plasma insulin and body weight were measured. Blood for glucose determinations during this experiment was taken from the tail vein, using the Glucometer II (Ames, Elkhart, IN, USA).

Hyperinsulinaemic, euglycaemic clamp. Hyperinsulinaemic, euglycaemic clamp studies were performed on non-anaesthetized, unstressed, chronically catheterized animals according to the method of Rossetti and Giaccari [13]. Animals from selected diabetes-prone and diabetes-resistant lines [11] were used. The surgical insertion of the catheters was performed 58 days before the clamp study. Psammomys and albino rats were anaesthetized with an i.p. injection of sodium pentobarbital $(60 \mathrm{mg} / \mathrm{kg})$. Indwelling catheters were inserted into the right jugular vein and the left carotid artery. On the day of experiment in the overnight fasted animals, a prime-continuous infusion of $6 \mu \mathrm{Ci} 3-{ }^{3} \mathrm{H}-\mathrm{D}$-glucose $(14 \mathrm{Ci} / \mathrm{mmole}$; New England Nuclear, Boston, MA, USA) was initiated and then a continuous infusion of $3-{ }^{3} \mathrm{H}-\mathrm{D}$-glucose at a rate of $0.2 \mu \mathrm{Ci} / \mathrm{min}$ for $40 \mathrm{~min}$ was carried out in order to allow steady state of the glucose tracer to be established. Blood samples were taken for measurements of glucose turnover and the calculation of basal hepatic glucose production (HGP). Human insulin (Actrapid HM; NovoNordisk, Bagsvaerd, Denmark) was then infused, first as a bolus of $4.4 \mathrm{mU}$ and then at a constant rate of $18 \mathrm{mU} \cdot \mathrm{min}^{-1} \cdot \mathrm{kg}^{-1}$. A $25 \%$ glucose solution was infused. The constant infusion of $2 \mu \mathrm{Ci} 3-{ }^{3} \mathrm{H}-\mathrm{D}$-glucose and insulin was performed together. Blood samples were taken every $10 \mathrm{~min}$ to measure blood glucose levels and maintain euglycaemia by adjusting the glucose infusion rate. Basal glucose turnover, insulin-stimulated total rate of glucose disappearance and HGP were measured as described by Rossetti and Giaccari [13].

Assays. Liver phosphoenolpyruvate carboxykinase (PEPCK) activity was measured as described previously [14]. Glucose 6phosphatase (G6Pase) activity was measured in isolated liver microsomes treated with $0.25 \%$ deoxycholic acid according to Burchell et al. [15]. Liver glycogen was determined enzymatically [16] after digestion of a portion of liver in $33 \%$ potassium hydroxide and precipitation of the glycogen by ethanol.

Plasma glucose and triglycerides were measured by an enzymatic method (Roche, Basel, Switzerland). Plasma insulin was measured by radioimmunoassay utilizing anti-human insulin antibodies (Medgenix, Brussels, Belgium) and human insulin as standard. Dilutions of Psammomys serum and pancreatic insulin gave curves paralleling those of dilutions of human insulin. Cross-reactivity with purified human insulin used as standard was 90-95\% [7].

Statistical analysis. All values are given as means \pm SEM. Group comparisons were made by paired Student's $t$-test. A significant difference was considered at $p<0.05$.

\section{Results}

Diabetes does not occur in Psammomys on the LE diet which is similar in its caloric value to the natural food regimen of this animal [11]. Although the metabolic efficiency of Psammomys is similar on both LE and $\mathrm{HE}$ diets [11], diabetes develops on the regular rodent (HE) diet because of the relative excess nutrient availability resulting in enhanced insulin secretion [3]. On the HE diet the transition from the normoinsulinaemic, normoglycaemic state one to the hyperglycaemic state three is often rapid, and may occur within 1-2 weeks.

To examine whether deficiency of bioactive insulin is a possible cause of the hyperglycaemic state, we administered s.c. implants supplying exogenous insulin to non-diabetic state A Psammomys. At the same time we started feeding them the HE diet that triggers diabetes.

Long-term exogenous insulin administration. In the first experiment, we examined Psammomys and albino rats treated with exogenous insulin from the day of weaning (average weight $45 \mathrm{~g}$ ) for 14 days and 


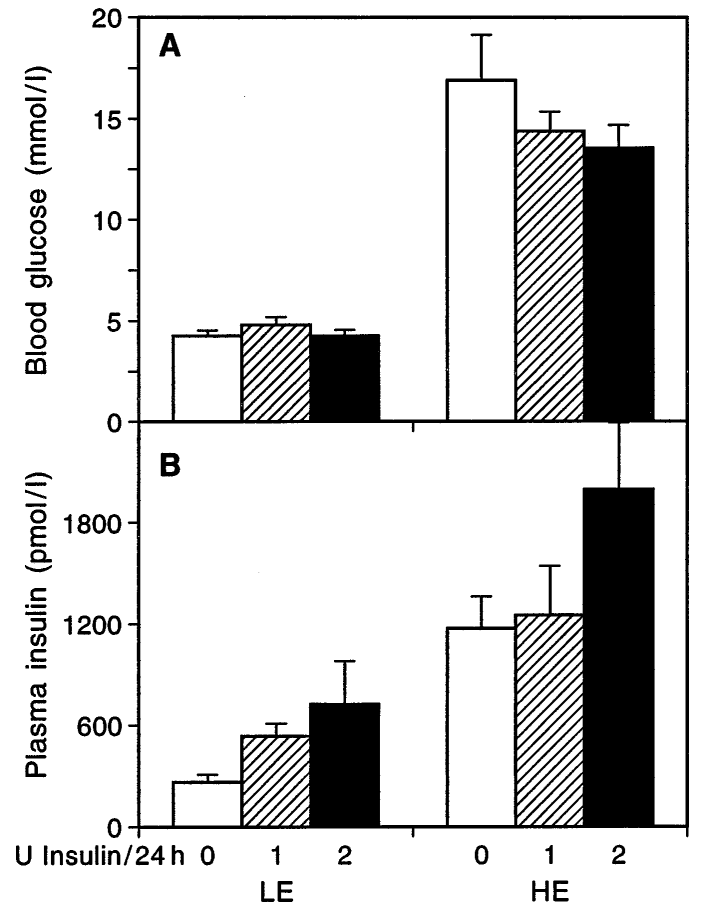

Fig. 1. A, B Effect of low (LE) and high (HE) energy diets and of exogenous insulin implants on A: blood glucose levels; B: plasma insulin levels in Psammomys after 14 days of treatment. No exogenous insulin $(\square), 1 \mathrm{U} / 24 \mathrm{~h}$ of exogenous insulin $(\mathbb{Z}), 2 \mathrm{U} / 24 \mathrm{~h}$ of exogenous insulin $(\square)$. Data presented are means $\pm \operatorname{SEM}(n=6)$

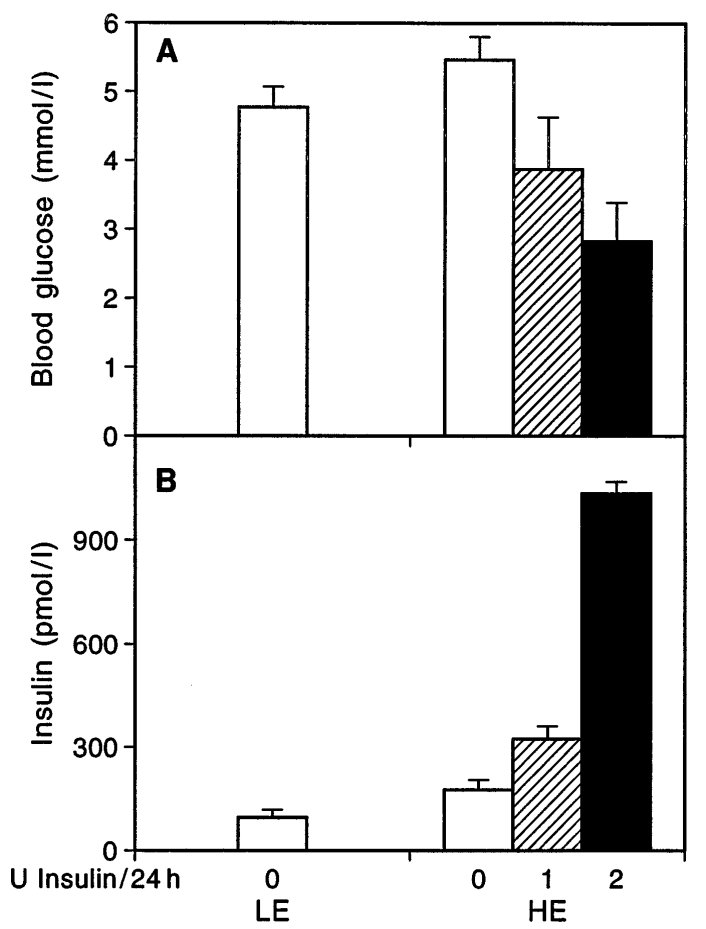

Fig. 2. A, B Effect of low (LE) and high (HE) energy diets and of exogenous insulin implants on A: blood glucose levels; B: plasma insulin levels in albino rats after 14 days of treatment. No exogenous insulin $(\square), 1 \mathrm{U} / 24 \mathrm{~h}$ of exogenous insulin $(\mathbb{Z}), 2 \mathrm{U} / 24 \mathrm{~h}$ of exogenous insulin $(\square)$. Data presented are means $\pm \operatorname{SEM}(n=6)$. All rats kept on LE diet succumbed to hypoglycaemia within $24 \mathrm{~h}$

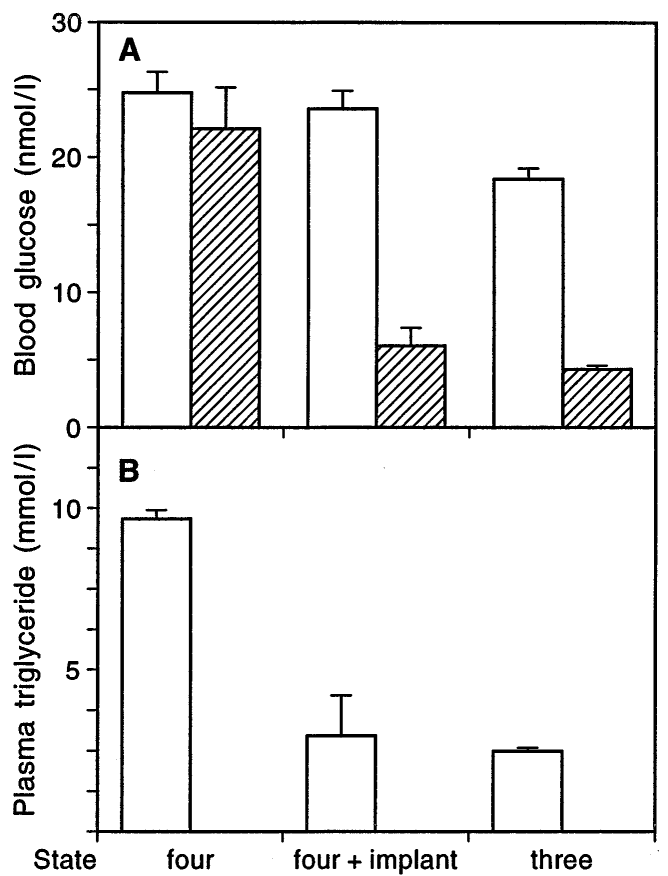

Fig. 3. A, B Effect of exogenous insulin implants on A: blood glucose levels; B: plasma triglyceride levels of state four Psammomys. Fed $(\square)$, fast (ख). Data are means \pm SEM $(n=10)$

maintained on the HE diet. The influence of exogenous insulin on blood glucose and serum insulin levels in Psammomys is shown in Figure 1. The HE diet caused hyperglycaemia and the treatment with exogenous insulin did not produce hypoglycaemia and failed to prevent the development of hyperglycaemia (Fig.1 A). Psammomys fed the LE diet and receiving exogenous insulin did not become hypoglycaemic despite a marked elevation in circulating insulin levels (Fig. 1B).

In contrast to Psammomys, albino rats fed the HE diet remained normoglycaemic, but exogenous insulin caused a pronounced decrease in their blood glucose levels (Fig. 2). On the LE diet the rats also maintained normoglycaemia but exogenous insulin caused a severe hypoglycaemia and the death of all animals within $24 \mathrm{~h}$. Insulin levels in rats both on the LE and the HE diet increased markedly as a result of exogenous insulin treatment, which, however, did not result in fatal hypoglycaemia on the HE diet (Fig. 2B).

The lack of effect of exogenous bovine insulin implants on blood glucose levels in Psammomys leads to asking whether exogenous insulin is biologically active in this animal even if it shows a significant crossreaction with Psammomys insulin. To test the efficacy of insulin, blood glucose and serum triglyceride levels were measured in state four Psammomys, deficient in endogenous insulin, in which the mean blood glucose level in the fasted state was $22 \mathrm{mmol} / \mathrm{l}$ and the plasma triglyceride level was $7.8 \mathrm{mmol} / \mathrm{l}$ (Fig. 3). The in vivo effect of the s. c. implants of exogenous insulin became 
Table 1. Effect of exogenous hyperinsulinaemia induced by $24 \mathrm{~h}$ slow-release insulin implants on serum glucose levels and enzymes related to gluconeogenesis in Psammomys and albino rats

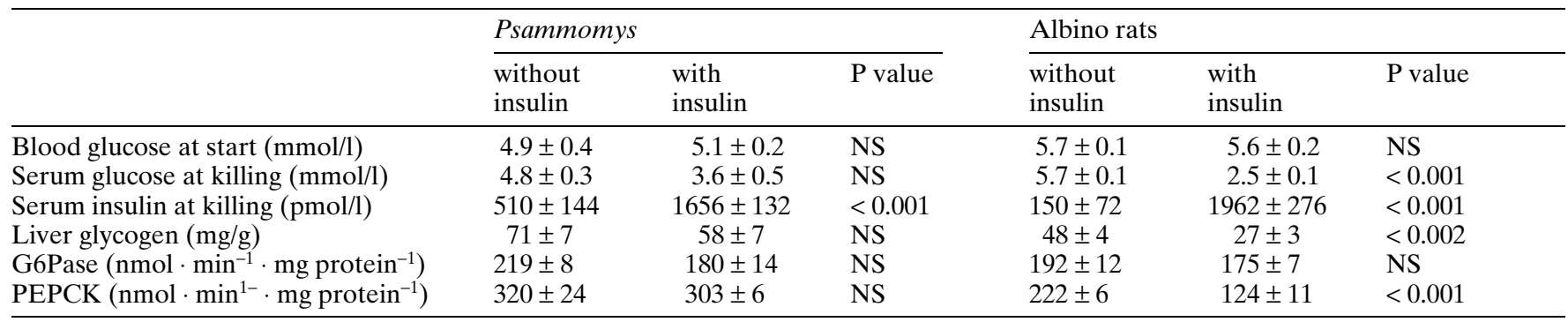

Values are means \pm SEM for groups of six animals.

NS, Non significant. All measurements were made in ad libitum fed animals on samples taken between 09.00 and 11.00 hours

Table 2. Hyperinsulinaemic euglycaemic clamp in Psammomys obesus and Albino rats

\begin{tabular}{lccl}
\hline & $\begin{array}{l}\text { Psammomys } \\
\text { diabetes- } \\
\text { prone } \\
(n=16)\end{array}$ & $\begin{array}{l}\text { Psammomys } \\
\text { diabetes- } \\
\text { resistant } \\
(n=4)\end{array}$ & $\begin{array}{l}\text { Albino } \\
\text { rat }\end{array}$ \\
\hline $\begin{array}{l}\text { Clamp plasma glucose } \\
(\mathrm{mmol} / \mathrm{l})\end{array}$ & $4.9 \pm 0.2$ & $5.2 \pm 0.3$ & $5.3 \pm 0.2$ \\
$\begin{array}{l}\text { Clamp plasma insulin } \\
(\mathrm{pmol} / \mathrm{l})\end{array}$ & $1453 \pm 132$ & $1200 \pm 522$ & $834 \pm 96$ \\
$\begin{array}{l}\mathrm{Basal} \mathrm{HGP} \\
\left(\mathrm{mg} \cdot \mathrm{min}^{-1} \cdot \mathrm{kg}^{-1}\right)\end{array}$ & $10.0 \pm 0.6$ & $8.9 \pm 1.7$ & $11.0 \pm 0.5$ \\
$\begin{array}{l}\text { Insulin HGP } \\
\left(\mathrm{mg} \cdot \mathrm{min}^{-1} \cdot \mathrm{kg}^{-1}\right)\end{array}$ & $3.8 \pm 0.4$ & $4.2 \pm 0.2$ & $0.7 \pm 0.3^{\mathrm{a}}$ \\
$\begin{array}{l}\text { Total glucose transport } \\
\left(\mathrm{mg} \cdot \mathrm{min}^{-1} \cdot \mathrm{kg}^{-1}\right)\end{array}$ & $16.0 \pm 1.9$ & $11.8 \pm 2.1$ & $39.0 \pm 1.9^{\mathrm{a}}$ \\
\hline
\end{tabular}

Values are means \pm SEM for the number of animals indicated in parentheses

Body weight of Psammomys and albino rats ranged between 150 and $190 \mathrm{~g}$. Fasting plasma glucose of Psammomys and albino rats was from $4.2 \pm 0.2$ to $4.4 \pm 0.2 \mathrm{mmol} / \mathrm{l}$ and plasma insulin was from $30 \pm 12$ to $42 \pm 12 \mathrm{pmol} / \mathrm{l}$.

${ }^{a} p<0.001$ for difference between albino rats and both Psammomys groups. No significant difference for all values between diabetes-prone and diabetes-resistant Psammomys

evident by the decrease of fasting glucose levels in four Psammomys to $5.9 \pm 1.2 \mathrm{mmol} / 1$ and fasting plasma triglyceride to $2.3 \pm 0.1 \mathrm{mmol} / \mathrm{l}$. Blood glucose levels in the fed state remained high $(23.2 \pm 1.3 \mathrm{mmol} / \mathrm{l})$, most probably due to the resistance to both endogenous and exogenous insulin.

Short-term exogenous insulin administration. Insulin implants were inserted s.c. to groups of 7-week-old Psammomys (state one, average weight $143 \mathrm{~g}$ ) and 5week-old albino rats (average weight $142 \mathrm{~g}$ ). The animals were killed $24 \mathrm{~h}$ later having an ad libitum access to LE diet and water throughout the experiment. Serum insulin and glucose levels are listed in Table 1. Both Psammomys and albino rats exhibited a marked hyperinsulinaemia of similar magnitude; however, Psammomys showed only a mild reduction in plasma glucose levels, whereas rats experienced a marked hypoglycaemia (Table 1).
The compensatory response to hypoglycaemia was different in Psammomys and rats. The reduction in liver glycogen content was mild in Psammomys but considerable in rats. Changes in the activity of gluconeogenic enzymes also showed a different response pattern. In Psammomys there was no significant decrease in hepatic PEPCK activity in the presence of exogenous hyperinsulinaemia; whereas in rats there was a significant suppression of PEPCK activity (Table 1). Little change was observed in the activity of G6Pase in either Psammomys or rats.

In another short-term experiment lasting $3 \mathrm{~h}$, double-strength insulin implants were inserted s.c. into Psammomys and rats. A hyperinsulinaemia of $5520 \pm 648$ and $6504 \pm 1758 \mathrm{pmol} / \mathrm{l}$, respectively, was elicited as determined at killing. Serum glucose in rats fell from $6.0 \pm 0.3$ to as low as $0.9 \pm 0.2 \mathrm{mmol} / \mathrm{l}$ $(p<0.001)$ in rats whereas in Psammomys only a mild decrease from $4.3 \pm 0.1$ to $3.4 \pm 0.2 \mathrm{mmol} / 1$ was recorded. Liver PEPCK activity was not significantly affected in Psammomys despite the pronounced hyperinsulinaemia $\left(384 \pm 40\right.$ vs $349 \pm 50 \mathrm{mmol} \cdot \mathrm{min}^{-1}$. $\left.\mathrm{mg}^{-1}\right)$. However, in rats a significant decrease in PEPCK activity was noted $(289 \pm 33$ vs $192 \pm 28 \mathrm{mmol}$. $\left.\mathrm{min}^{-1} \cdot \mathrm{mg}^{-1}, p<0.05\right)$.

Hyperinsulinaemic euglycaemic clamp. To define better the nature of the insulin resistance and to assess the effect of exogenous insulin on HGP and total glucose disposal in state A Psammomys maintained on the LE diet, a hyperinsulinaemic, euglycaemic clamp was performed. The clamp was carried out on groups of Psammomys both of the diabetes-prone and diabetes-resistant lines [11] (Table 2).

Psammomys and albino rats were matched for weight ( $155 \pm 4$, and $158 \pm 7 \mathrm{~g}$ respectively). The basal fasting glucose and insulin levels were similar in all animals. The hyperinsulinaemia resulting from the infusion of an identical amount of insulin was higher in Psammomys than in rats by $44-74 \%$, due to low hepatic clearance $[8,17]$. The basal HGP in albino rats and in both groups of Psammomys was similar in magnitude. However, in albino rats the HGP became almost completely suppressed by exogenous insulin, 
whereas in the two groups of Psammomys the mean reduction was 62 to $53 \%$, respectively. It should be also stressed that the incomplete HGP suppression was evident despite longer insulin infusion time $(90$ vs $60 \mathrm{~min}$ in rats) and higher circulating insulin levels. The total glucose uptake (TGT) effected by hyperinsulinaemia was $39.0 \pm 1.9 \mathrm{mg} \cdot \mathrm{min}^{-1} \cdot \mathrm{kg}^{-1}$ in rats, whereas it was lower by 30 to $41 \%$ in Psammomys, in spite of higher circulatory insulin levels.

\section{Discussion}

Psammomys obesus develops a pronounced insulin resistance both at muscle and liver levels when maintained on a high energy laboratory diet as compared with its native regimen. This is evident from decreased deoxyglucose uptake [7] and lack of restraint of hepatic gluconeogenesis in the face of hyperinsulinaemia [18]. Insulin-induced receptor activation, a prerequisite for intracellular signal transduction is inhibited in the hyperinsulinaemic-hyperglycaemic state, indicating that the resistance is located at the receptor site [8].

We have demonstrated here that the insulin resistance in Psammomys obesus may be an inherent species characteristic even in the normoglycaemic-normoinsulinaemic state A on the LE diet. Several experiments in which plasma insulin was raised by the administration of exogenous insulin did not result in marked hypoglycaemia. External insulin is effective in Psammomys as demonstrated in its hypoglycaemic and hypotriglyceridaemic effect in insulin-deficient Psammomys in state D. Psammomys at state D with exogenous insulin, become metabolically similar to the insulin-resistant state C Psammomys, characterized by endogenous hyperinsulinaemia. Thus, despite the strong hypoglycaemic and hypotriglyceridaemic effect, the superimposed exogenous insulin is not capable of lowering blood glucose levels in the non-fasting state C Psammomys with pronounced elevated endogenous insulin.

The ability of Psammomys to withstand the hypoglycaemic effect of insulin implants could not be explained by massively increased hepatic gluconeogenesis or glycogenolysis. However, because hepatic PEPCK, the rate limiting gluconeogenic enzyme, was reduced only in part by hyperinsulinaemia, indicates that gluconeogenesis was proceeding and could compensate for the insulin-induced peripheral glucose uptake. It is also conceivable that the scarcity of hepatic and muscle insulin receptors in this animal species and their compromised function in the presence of hyperinsulinaemia [8] did not result in an excessive plasma glucose removal. In contrast, the similar hyperinsulinaemia in albino rats resulted in reduced hepatic gluconeogenic capacity and enhanced glycogenolysis, which however did not appear to be sufficient to compensate for the insulin-stimulated tissue glucose uptake. Thus, a profound hypoglycaemia was evident, particularly when the animals were maintained on the LE diet.

The use of rats as reference animals in parallel with Psammomys does not imply that they are control animals. They reflect a response of a different species population well adjusted to the HE laboratory diet and characterized by marked sensitivity to insulin.

Our premise of liver and muscle insulin resistance as a species characteristic of Psammomys was confirmed by quantitative data on HGP and TGT in hyperinsulinaemic, euglycaemic clamp studies. Insulin infusion decreased the HGP and increased the TGT, again demonstrating the effectiveness of the exogenous insulin. However, HGP was only partly reduced, whereas in albino rats HGP was almost completely abolished. Lack of complete suppression of HGP in Psammomys was evident even at a higher and longer lasting level of hyperinsulinaemia than in the rats, confirming our previous assumption that gluconeogenesis in Psammomys treated with insulin implants is sustained despite hyperinsulinaemia. Also the limited elevation of TGT in the clamped Psammomys attests to the fact that the peripheral glucose utilization was low and was compensated by gluconeogenesis avoiding a lapse into hypoglycaemia during exogenous insulin administration.

In a previous communication [9] a high proportion of circulating proinsulin was observed particularly in the hyperglycaemic, hyperinsulinaemic state $\mathrm{C}$ Psammomys. The hyperproinsulinaemia was elicited most probably by the pancreatic beta-cell over-taxation as a result of protracted hyperglycaemia. This finding raised the question to what extent the availability of biologically active insulin is reduced to account for the hyperglycaemia or whether hyperglycaemia is caused mainly by the peripheral and hepatic resistance to the available active insulin. It could be postulated that in the presence of a high proportion of proinsulin or partially split insulin (known to have low bioactivity) in Psammomys, the HGP could not be totally suppressed in vivo and the peripheral glucose utilization could not be adequately promoted, thus resulting in hyperglycaemia. However, the present experiments with exogenous insulin, derived either from implants or from infusion during clamp studies, indicate that the hyperinsulinaemia elicited by the nutritional overload in states $\mathrm{B}$ or $\mathrm{C}$ is able to suppress the HGP at least in part. Full suppression, as observed in the rats, could not be achieved because of the particular resistance of the Psammomys species rather than to insufficient levels of bioactive insulin resulting from the change in the insulin/proinsulin ratio. Similar observations on incomplete suppression of HGP by porcine insulin were also observed in another group of Psammomys 
in contrast to the complete suppression in Sprague Dawley rats (K.Zakrzewska and B.Jeanrenaud personal communication). Lack of total HGP suppression in Psammomys was evident in these hyperinsulinaemic clamp studies even at plasma levels of infused insulin exceeding $6000 \mathrm{pmol} / \mathrm{l}$.

Gluconeogenesis is the most important pathway for the replenishment of plasma glucose and has a predominant role in the increased HGP, eliciting hyperglycaemia in patients with NIDDM [19-21]. Excessive HGP rather than decreased glucose utilization was also found to account for the hyperglycaemia in rats with streptozotocin-induced diabetes [22]. Moreover, hyperglycaemia due to enhanced HGP has been observed to persist despite hyperinsulinaemia in a variety of situations both in humans and animals, some of them associated with obesity [23].

The observation that HGP was only partially reduced both in diabetes-prone and diabetes-resistant Psammomys during clamp hyperinsulinaemia raised the question as to the nature of the different responses of these lines to the high energy nutritional regimen. It has previously been shown that hyperinsulinaemia is detrimental to the activity of insulin receptors, and the density of liver and muscle receptors in randomly chosen Psammomys is low [8]. The difference in hyperglycaemic response between the two selected lines may be related to the insulin secretion response of pancreatic beta-cells on the high energy diet, the amount of available insulin receptors, or the rate of liver clearance of circulating insulin. These aspects are under current investigation.

Our findings of limited suppressibility of HGP by hyperinsulinaemia in Psammomys, might contribute to the understanding of the metabolic conditions in the desert environment. With meagre nutrition any glucose derived from non-glucose precursors would be primarily targeted to the vital glucose-dependent tissues and the released insulin should not be able to shut off the gluconeogenesis. HGP in the desert environment is probably of survival value both in terms of preferential glucose channelling to non-insulin-dependent nervous tissues and conversion of the available glucose to energy storage, e.g. hepatic lipogenesis. It is quite possible that the adaptation of both animals and humans to plentiful nutrition either in laboratory conditions or as a result of affluence of the western lifestyle have attenuated or selected out the "inborn" insulin resistance characteristics of populations living in nutritional scarcity [24]. Absence of gluconeogenesis restraint in such populations together with rich nutrient intake would lead to enhancement of insulin secretion, excessive lipogenesis followed by insulin resistance and hyperglycaemia. This, and eventual obesity with potentiation of insulin resistance is well exemplified in Psammomys because of the abundant hepatic lipogenic capacity and adipose tissue triglyceride uptake [25].
Acknowledgements. This work was supported in part by the grant from Chief Scientist of the Israeli Ministry of Health and by donations from Mr. D. Chase, Hartford, CT, USA, and Mr. E.Porter, Kansas City, Mo, USA. We wish to thank Ms. G. Lazarovici for excellent assistance in animal studies.

\section{References}

1. Shafrir E (1992) Animal models of non-insulin-dependent diabetes. Diabetes Metab Rev 8: 179-208

2. Shafrir E, Gutman A (1993) Psammomys obesus of the Jerusalem colony: a model for nutritionally induced non-insulin-dependent diabetes. J Basic Clin Physiol Pharmacol 4: 83-99

3. Ziv E, Shafrir E (1995) Psammomys obesus: nutritionally induced NIDDM-like syndrome on a "thrifty gene" background. In: Shafrir E (ed) Lessons from animal diabetes, Vol5. Smith-Gordon, London pp 285-300

4. Swinburn BA, Boyce VL, Bergman RN, Howard BV, Bogardus C (1991) Deterioration in carbohydrate metabolism and lipoprotein changes induced by modern, high fat diet in Pima Indians and Caucasians. J Clin Endocrinol Metab 73: 156-165

5. Zimmet P (1982) Type 2 (non-insulin-dependent) diabetes - an epidemiological overview. Diabetologia 22: 399-411

6. O’Dea K, Traianedes K, Hopper JL, Larkins RG (1988) Impaired glucose tolerance, hyperinsulinemia, and hypertriglyceridemia in Australian Aborigines from the desert. Diabetes Care 11: 23-29

7. Kalderon B, Gutman A, Levy E, Shafrir E (1986) Characterization of stages in the development of the obesity-diabetes syndrome in sand rat (Psammomys obesus). Diabetes 35: 717-724

8. Kanety H, Moshe S, Shafrir E, Lunenfeld B, Karasik A (1994) Hyperinsulinemia induces a reversible impairment in insulin receptor function leading to diabetes in the sand rat model of non-insulin-dependent diabetes mellitus. Proc Natl Acad Sci USA 91: 1853-1857

9. Gadot M, Leibowitz G, Shafrir E, Cerasi E, Gross DJ, Kaiser N (1994) Hyperproinsulinemia and insulin deficiency in the diabetic Psammomys obesus. Endocrinology 135: 610 616

10. Bendayan M, Malide D, Ziv E et al. (1995) Immunocytochemical investigation of insulin secretion by pancreatic $\beta$ cells in control and diabetic Psammomys obesus. J Histochem Cytochem 43: 771-784

11. Kalman R, Adler JH, Lazarovici G, Bar-On H, Ziv E (1993) The efficiency of sand rat metabolism is responsible for development of obesity and diabetes. J Basic Clin Physiol Pharmacol 4: 57-68

12. Wang PY (1989) Implantable reservoir for supplemental insulin delivery on demand by external compression. Biomaterials 10: 197-201

13. Rossetti L, Giaccari A (1990) Relative contribution of glycogen synthesis to insulin-mediated glucose uptake. A dose-response euglycemic clamp study in normal and diabetic rats. J Clin Invest 85: 1785-1792

14. Krausz Y, Bar-On H, Shafrir E (1981) Origin and pattern of glucocorticoid-induced hyperlipidemia in rats. Dose-dependent bimodal changes in serum lipids and lipoproteins in relation to hepatic lipogenesis and tissue lipoprotein lipase activity. Biochim Biophys Acta 63: 69-82

15. Burchell A, Hume R, Burchell B (1988) A new microtechnique for the analysis of the human hepatic microsomal glucose-6-phosphatase system. Clin Chim Acta 173: 183192 
16. Johnson JA, Fusaro RM (1964) An enzymatic method for the quantitative determination of micro quantities of glycogen. Anal Biochem 7: 189-191

17. Ziv E, Adler JH, Lior O, Bar-On H (1986) Insulin uptake by the liver of the sand rat. Diabetes 35: 158 A (Abstract)

18. Shafrir E (1988) Nonrecognition of insulin as gluconeogenesis suppressant - a manifestation of selective hepatic resistance in several animal species with type II diabetes: sand rats, spiny mice and db/db mice. In: Shafrir E, Renold AE (eds) Lessons from animal diabetes, Vol2. J.Libbey, London pp 304-315

19. Fery F (1994) Role of hepatic glucose production and glucose uptake in the pathogenesis of fasting hyperglycemia in type 2 diabetes: normalization of glucose kinetics by short term fasting. J Clin Endocrinol Metab 78: 536-542

20. Consoli A, Nurihan N, Capani F, Gerich J (1989) Predominant role of gluconeogenesis in increased hepatic glucose production in NIDDM. Diabetes 38: 550-557
21. Prager R, Wallace P, Olefsky MJ (1987) Direct and indirect effects of insulin to inhibit hepatic glucose output in obese subjects. Diabetes 36: 607-611

22. Burcelin R, Eddouks M, Maury J, Kande J, Assan R, Girard J (1995) Excessive glucose production, rather than insulin resistance, accounts for hyperglycaemia in recent-onset streptozotocin-diabetes rats. Diabetologia 38: 283-290

23. Cusin I, Rohner-Jeanrenaud F, Terrettaz J, Jeanrenaud B (1992) Hyperinsulinemia and its impact on obesity and insulin resistance. Int J Obes 16 [Suppl 4]: S1-S11

24. Brand Miller JC, Colagiuri S (1994) The carnivore connection: dietary carbohydrate in the evolution of NIDDM. Diabetologia 37: 1280-1286

25. Kalderon B, Adler JH, Levy E, Gutman A (1983) Lipogenesis in the sand rat (Psammomys obesus). Am J Physiol 244: E480-E486 